\section{Stabilization of stalled DNA replication forks by the BRCA2 breast cancer susceptibility protein}

\author{
Mikhail Lomonosov, Shubha Anand, \\ Mahesh Sangrithi, Rachel Davies, and \\ Ashok R. Venkitaraman ${ }^{1}$
}

University of Cambridge, CR UK Department of Oncology and The Medical Research Council Cancer Cell Unit, Hutchison/MRC Research Centre, Cambridge CB2 2XZ, UK

How dividing mammalian cells overcome blocks to DNA replication by DNA damage, depleted nucleotide pools, or template-bound proteins is unclear. Here, we show that the response to blocked replication requires BRCA2, a suppressor of human breast cancer. By using two-dimensional gel electrophoresis, we demonstrate that Y-shaped DNA junctions at stalled replication forks disappear during genome-wide replication arrest in BRCA2-deficient cells, accompanied by double-strand DNA breakage. But activation of the replication checkpoint kinase Chk2 is unaffected, defining an unexpected function for BRCA2 in stabilizing DNA structures at stalled forks. We propose that in BRCA2 deficiency and related chromosomal instability diseases, the breakdown of replication forks, which arrest or pause during normal cell growth, triggers spontaneous DNA breakage, leading to mutability and cancer predisposition.

Received July 11, 2003; revised version accepted October 28, 2003.

Germline mutations in BRCA2 cause breast, ovarian, and other cancers with a penetrance estimated at $85 \%$ by age 70 years (Nathanson et al. 2001). Although the precise activities of BRCA2 protein relevant to tumor suppression are uncertain (Scully and Livingston 2000), lossof-function mutations cause spontaneous instability of chromosome structure in dividing cells /Gretarsdottir et al. 1998; Patel et al. 1998), reminiscent of inherited diseases, such as Bloom syndrome and Fanconi anemia (Patel et al. 1998), also associated with cancer predisposition. Notably, the chromosomal instability induced by BRCA2 disruption frequently triggers aberrations thought to arise during replication of a damaged template (Scully and Livingston 2000; Venkitaraman 2000), including chromatid breaks and triradial and quadriradial chromosomes (Patel et al. 1998). These structural abnormalities are characterized by inappropriate genetic exchanges between nonhomologous chromosomes, causing gross chromosomal rearrangements (GCRs) such as

[Keywords: Cancer susceptibility; cell cycle checkpoints; chromosome structure; DNA replication; genetic instability] ${ }^{1}$ Corresponding author.

E-MAIL arv22@cam.ac.uk; FAX 44-1223-763374.

Article published online ahead of print. Article and publication date are at http://www.genesdev.org/cgi/doi/10.1101/gad.279003. translocations or deletions (Yu et al. 2000), often found in human cancer cells. Thus, BRCA2 serves as a "caretaker" of chromosomal integrity through participation in processes linked to DNA replication. But what these BRCA2-dependent processes may be is unknown.

In yeast models, spontaneous chromosomal breaks and GCRs occur in mutant strains deficient in the response to stalled or incomplete DNA replication /Chen and Kolodner 1999; Myung et al. 2001). Circumstantial evidence connects BRCA2 with this response in mammalian cells. Although it does not usually colocalize with components of the mammalian replication machinery, BRCA2 moves into PCNA-containing nuclear foci when replication is blocked (Chen et al. 1998). These findings hint at the involvement of BRCA2 in processes activated by replication inhibition. Here, we report a novel role for BRCA2.

\section{Results and Discussion}

Disappearance of replication forks after replication stalling

Hydroxyurea (HU) mimics the effects of genome-wide blocks to replication (Enoch et al. 1992; Zhao et al. 1998; Alcasabas et al. 2001) by inhibiting ribonucleotide reductase, depleting precursor pools for DNA synthesis. To define the function of BRCA2 in the response to $\mathrm{HU}$, we used murine embryonal fibroblasts (MEFs) homozygous for a targeted truncation in $B R C A 2(B R C A 2 \operatorname{Tr} / \operatorname{Tr})$. This allele, designed to mimic mutations associated with ovarian cancers, disrupts the function of BRCA2 in cell division, chromosomal stability, DNA repair, and tumor suppression (Friedman et al. 1998; Patel et al. 1998). As controls, we used MEFs derived from the same genetic background, but wild type for BRCA2 $\left(B R C A 2^{++}\right)$. The division of BRCA2 Tr/Tr MEFs is relatively normal for the first 4 to $6 \mathrm{~d}$ in culture, but thereafter, they exhibit a progressive impediment (Patel et al. 1998).

We visualized replication intermediates by two-dimensional (2D) gel electrophoresis (Friedman and Brewer 1995) in a region of the ribosomal DNA (rDNA) locus during HU treatment. About 200 copies of the rDNA genes are present in each diploid genome, enabling detection of rare DNA intermediates (Gogel et al. 1996; Gerber 1997). We examined a region (Fig. 1A) adjacent to the origin of bidirectional replication (OBR; but excluding the known replication fork barrier [RFB]), visualizing replication forks progressing unidirectionally within the 45S rDNA precursor sequence (Gogel et al. 1996; Gerber 1997). Fork progression should give rise to an arc of Yshaped DNA intermediates, originating with linear unreplicated DNA on the gel diagonal. The arc rises above the diagonal as forks move away from the origin (and the arms of the Y-shaped replication intermediates elongate), and returns to the diagonal when completed replication produces a V-shaped DNA molecule, which approximates to linear DNA with twice the molecular mass of the unreplicated segment (Fig. 1B).

These experiments were initially carried out in BRCA2Tr/Tr and control cells, in their first culture passage, synchronized by 12 -h exposure to a low dose $(1.4$ $\mu \mathrm{M})$ of aphidicolin, which slows replication, leading to synchronization in S phase (Dimitrova and Gilbert 


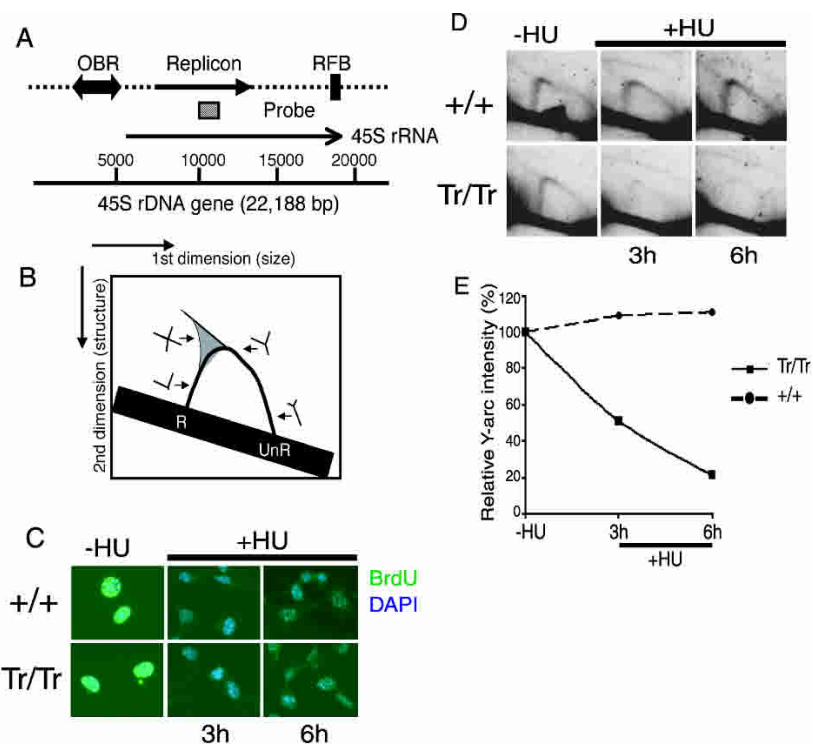

Figure 1. Analysis of rDNA replication by two-dimensional (2D) gel electrophoresis. $(A)$ Genomic structure of the murine rDNA repeat, scaled in bp. The origin of bidirectional replication (OBR) and the replication fork barrier (RFB) flank the 5446-bp ApaL1 restriction fragment analyzed in $D$ (thick line ending with an arrow in the top panel). A filled rectangle marks the hybridization probe used in Figs. 1D and 3A. (B) Replication intermediates detected by 2D gel electrophoresis. Y-shaped DNA junctions at replication forks rise off the diagonal to form the $\mathrm{Y}$-arc. A cone-shaped signal extending from the crest of the Y-arc represents four-way DNA junctions. Positions of unreplicated (UnR) and replicated (R) DNA are marked. (C) Firstpassage cells were synchronized as described, and released into $S$ phase for $6 \mathrm{~h}$ (-HU sample, ie., no HU treatment). HU was then added to $5 \mathrm{mM}$ concentration and samples taken at $3 \mathrm{~h}(+\mathrm{HU} 3 \mathrm{~h})$ and $6 \mathrm{~h}(+\mathrm{HU} 6 \mathrm{~h})$ during exposure. Nuclei were stained for replication foci (BrdU, 30' pulse, green), and for DNA (DAPI, blue). Apoptotic changes marked by Annexin V staining do not occur during HU treatment (data not shown). ( $D$ ) Replication intermediates from replication of the rDNA genes in S phase-synchronized cells, before and during HU treatment for up to $6 \mathrm{~h}$. Slight distortion of the Y-arc in the first panel $(+/+,-\mathrm{HU})$ is due to a tear in the gel. $(E)$ Relative intensities of the Y-arc signal in the different 2D gels (expressed as a densitometric ratio over signal on the gel diagonal to normalize for DNA loading) were plotted as a percentage of the value in S-phase cells before HU treatment. Standard deviations from the mean are too small to be visible.

2000). The Y-arcs formed during rDNA replication are similar in BRCA2Tr/Tr and control cells (Fig. 1C); thus, there is no requirement for BRCA2 during processive replication. Indeed, when replication fork progression through the rDNA replicon is compared between synchronized BRCA2-deficient or control cells by 2D gel electrophoresis at 2-6 h after release into $S$ phase, no significant differences are seen (data not shown). This indicates that BRCA2 inactivation per se does not enhance origin firing or fork progression, as recently observed in yeast lacking the Sgs1 helicase (Versini et al. 2003).

However, replication inhibition with $5 \mathrm{mM} \mathrm{HU}$, which inhibits DNA synthesis to the same extent in BRCA2-deficient and control cells as measured by incorporation of bromodeoxyuridine (BrdU; Fig. 1C) or $3 \mathrm{H}$ thymidine (Fig. 2B), gives rise to striking differences in the $2 \mathrm{D}$ gel patterns. In control BRCA $2^{+/+}$cells from 3 to $6 \mathrm{~h}$ after HU addition, the Y-arc representing stalled replication forks is little changed in intensity or conforma- tion, consistent with previous results (Levenson and Hamlin 1993). But in BRCA2Tr/Tr cells, the Y-arc rapidly diminishes and then almost disappears. Densitometric quantitation of the Y-arc signal, normalized as a ratio over signal on the gel diagonal to account for variations in DNA loading or gel exposure (Fig. 1D), confirms this. Similar changes, but to a lesser extent, are seen in an experiment carried out using asynchronous cell cultures (data not shown), ruling out the possibility that synchronization itself gives rise to differential changes in DNA structure in BRCA2Tr/Tr versus control cells.

\section{Synthesis and turnover of nascent DNA}

To examine differences in DNA synthesis before and after HU treatment, we measured the turnover of nascent DNA strands (Fig. 2). Genomic DNA in BRCA2Tr/Tr or control cells was first labeled to saturation by using 14Cthymidine, before the cells were synchronized by treatment with aphidicolin as before, and released into $S$ phase for $3 \mathrm{~h}$ (Fig. 2A). Thirty minutes before replication stalling through the addition of $\mathrm{HU}, 3 \mathrm{H}$-thymidine was added to label nascent DNA strands. HU treatment was carried out as before, in the continuing presence of $3 \mathrm{H}$ thymidine. Under these conditions, the ratio of $3 \mathrm{H}$ over 14C incorporation into DNA provides a measure of the synthesis or degradation of newly synthesized DNA at replication forks stalled by $\mathrm{HU}$. In BRCA2Tr/Tr cells, just as in controls, this ratio does not change significantly after HU treatment compared with its value before treatment (Fig. 2A). Thus, the disappearance of Yarcs is not due to extensive degradation of newly synthesised DNA (although limited, localized reactions cannot be ruled out).

The differential disappearance of Y-arcs in BRCA2-deficient but not control cells might also occur if BRCA2deficient cells were less sensitive to the replication blocking effects of $\mathrm{HU}$, and continued rapid DNA syn-

A
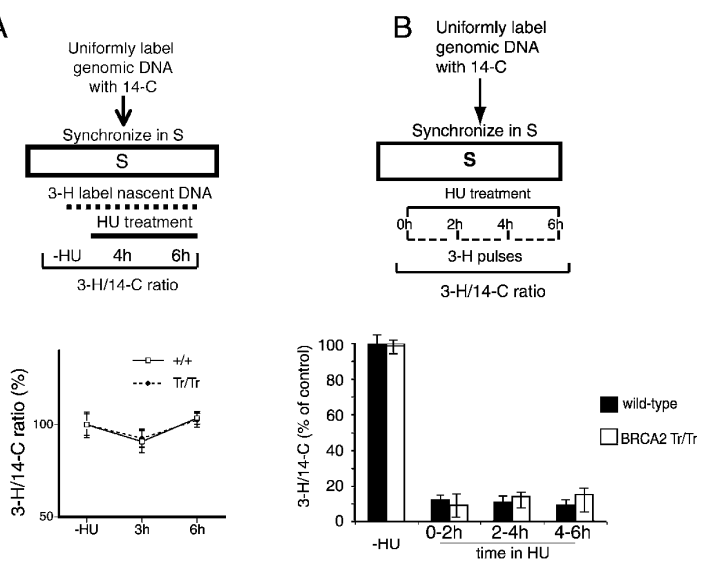

Figure 2. Nascent DNA synthesis and turnover after replication blockage. $(A)$ The experimental protocol used to detect nascent DNA turnover is outlined in the top panel, and explained in the text. The ratio of $3 \mathrm{H}$ labeling of nascent DNA over uniform 14C labeling of genomic DNA in synchronized cells before and during HU treatment is plotted as a percentage of the initial ratio. (B) Similarly, the protocol used to determine nascent DNA synthesis is outlined above the results. The ratio of $3 \mathrm{H}$ incorporation into nascent DNA over uniform $14 \mathrm{C}$ labeling is shown at $0-2 \mathrm{~h}, 2-4 \mathrm{~h}$, and $4-6 \mathrm{~h}$ during the 6-h course of HU treatment as a percentage of the ratio in untreated cells (-HU). 
thesis, thus completing replication of the rDNA fragment over the 6-h period analyzed. To test this, we uniformly labeled genomic DNA with 14C-thymidine, synchronized cells using aphidicolin, and released them into $S$ phase before treatment with HU as described previously (Fig. 2B). But in this experiment, the cells were pulsed with $3 \mathrm{H}$-thymidine for $2 \mathrm{~h}$ at different times $(0-2$ h, 2-4 h, or 4-6 h) during the course of 6-h HU treatment. As shown in Figure 2B, there is a small amount of $3 \mathrm{H}$ thymidine incorporation in HU-treated cells, consistent with previously published reports showing that HU profoundly slows but does not fully stop DNA replication (Levenson and Hamlin 1993; Cliby et al. 1998; Gao et al. 1998). Importantly, however, we observe no difference between BRCA2Tr/Tr versus control cells, ruling out the possibility that differential effects of HU on DNA synthesis account for the disappearance of Y-arcs in BRCA2deficient cells.

\section{Double-strand DNA breakage accompanies replication stalling}

An alternative explanation for the disappearance of Yarcs comes from observations on bacterial mutants deficient in DNA replication, in which arrested replication forks are processed into linear DNA fragments (Michel et al. 1997). Such a mechanism could be consistent with our data, which show that the Y-arc signal disappears in BRCA2-deficient cells, but without significant DNA synthesis or degradation. To test this idea, we looked for DNA fragments predicted to result from processing of forks stalled in the rDNA genes. High-molecular-weight genomic DNA from BRCA2Tr/Tr or control cells before or during HU treatment was resolved by pulsed-field gel electrophoresis (PFGE), and hybridized after Southern blotting to the same rDNA probe used to detect replication intermediates. Normally, chromosomal rDNA loci are too large to enter the gel, as observed in BRCA2 $2^{+/+}$ controls. In contrast, in BRCA2Tr/Tr cells treated with $\mathrm{HU}$, the detection of smaller rDNA fragments (Fig. 3A) confirms that there is breakdown of DNA in the genomic regions where we have shown Y-shaped DNA junctions at replication forks to collapse. The large mass $(\geq 6 \mathrm{Mb})$ of most of the DNA fragments, the absence of nucleosomal laddering patterns, and the lack of DNA degradation rule out apoptosis as a cause for DNA breakage.

The breakdown of stalled replication forks in BRCA2deficient cells treated with $\mathrm{HU}$ is not restricted to the rDNA genes. Ethidium bromide staining confirms the accumulation of broken DNA molecules of $\sim 6 \mathrm{Mb}$ (Fig. 3C,D), which can also be detected (Fig. 3E) by using probes proximal to a known bidirectional replication origin in the adenosine deaminase (ADA) genomic DNA locus (Carroll et al. 1993), or to a presumptive origin in the hypoxanthine-guanine phosphoribosyl transferase (HPRT) locus (Cohen et al. 2002). Genomic DNA breakage is dependent upon the dose of $\mathrm{HU}$ (Fig. 3F) and occurs in asynchronous cultures after HU treatment (data not shown). Interestingly, a small amount of DNA breakage occurs in BRCA2Tr/Tr cells even without HU addition (Fig. 3B,D), consistent with the notion that replication forks stalled at template lesions or natural pause sites during normal DNA replication undergo a fate similar to those in HU-treated cells.

We find that up to $50 \%$ of rDNA in pulsed-field gels,

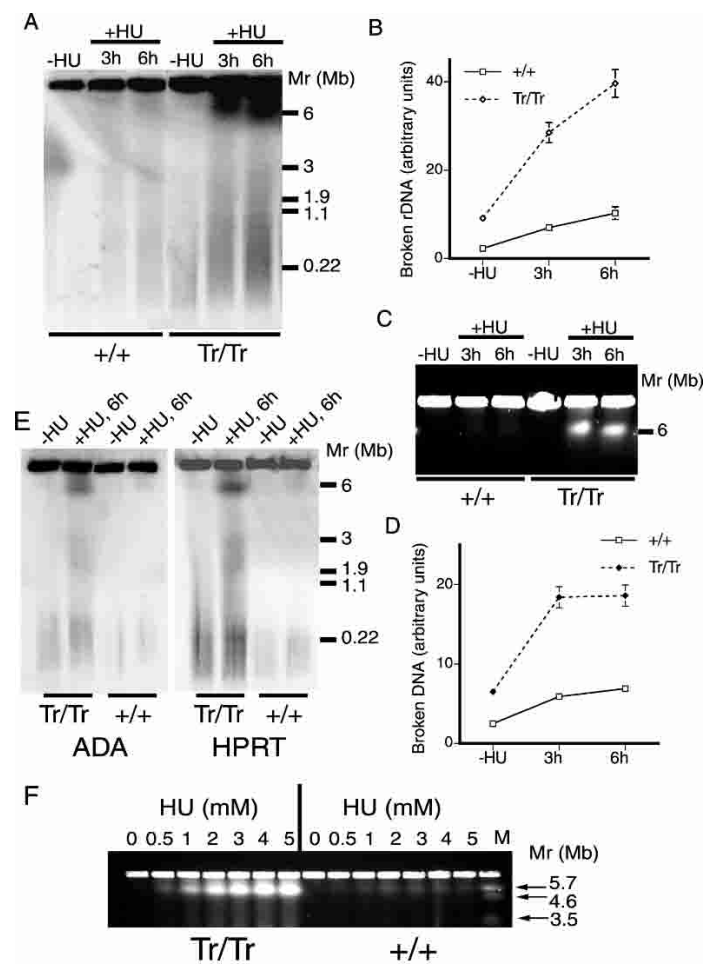

Figure 3. Breakdown of rDNA and genomic DNA after replication blockage. (A) PFGE showing broken rDNA in BRCA2Tr/Tr cells before and during HU treatment. The 325 -bp probe used to detect fragmentation is the same as that used in Fig. 1D to detect replication intermediates. Molecular-weight markers are shown in Mb. $(B)$ Relative intensity of broken rDNA entering the gel measured by densitometry is plotted in arbitrary units. Standard deviations from the mean value are marked when large enough to be visible. $(A, D)$ Relative amounts of broken chromosomal DNA detected by ethidium bromide staining were measured by densitometry and plotted in arbitrary units. (E) DNA breakage occurs in the ADA or HPRT genomic DNA loci of BRCA2Tr/Tr cells treated with HU under the same conditions used in panel $A$. $(F)$ DNA breakage detected by ethidium bromide staining is dependent on HU dose. Doses $\geq 5 \mathrm{mM}$ produce the same effect. Experiments are typical of at least two independent repeats.

detected with the same probe used to develop 2D gels (Fig. 1A), undergoes breakdown and enters the gel by 6 to $9 \mathrm{~h}$ after addition of $\mathrm{HU}$ (Fig. 3A). This is slightly less than the $\sim 80 \%$ disappearance of $\mathrm{Y}$-arcs at a similar time. Because the upper limit of resolution of the gels is $\sim 6$ $\mathrm{Mb}$, it is conceivable that not all large DNA fragments enter the gel, accounting for this difference. Alternatively, not all stalled replication forks in BRCA2-deficient cells may be processed into linear DNA fragments.

\section{Replication checkpoint arrest}

The Chk2 kinase, the mammalian ortholog of RAD53/ Cds1 in yeast, is essential for the checkpoint response activated by $\mathrm{HU}$ that prevents premature entry into mitosis before replication has been completed (Boddy et al. 1998; Chaturvedi et al. 1999; Hirao et al. 2000; Tercero and Diffley 2001). In yeast, this checkpoint response has been implicated in the stabilization of replication intermediates following HU-induced fork stalling (Lopes et al. 2001), because RAD53/Cds1 mutants accumulate abnormal replication intermediates that resemble four-way 
Holliday junctions at stalled replication forks. We therefore asked if BRCA2 disruption had prevented the activation of Chk2-dependent replication checkpoint mechanisms.

This is not so. BRCA2 $\operatorname{Tr} / \operatorname{Tr}$ cells efficiently maintain arrest in S phase during HU treatment (Patel et al. 1998; data not shown), do not prematurely enter mitosis as marked by staining for phosphorylated histone H3 (Fig. $4 \mathrm{~A})$, and are competent to trigger and maintain phosphorylation of Chk2 (Fig. 4B), a modification that marks activation of the kinase (Boddy et al. 1998; Chaturvedi et al. 1999). Interestingly, in BRCA2-deficient cells, some Chk2 phosphorylation occurs even before the addition of $\mathrm{HU}$ and persists for up to $4 \mathrm{~h}$ after release of cells from HU-induced arrest, suggesting that DNA structures that activate Chk2 occur or persist under these conditions. Indeed, broken DNA remains detectable for up to $3 \mathrm{~h}$ after release from HU (Fig. 4C), but at steadily declining levels, suggestive of resolution by BRCA2-independent mechanisms such end-joining, which could provoke chromosomal rearrangements (Yu et al. 2000). After removal of HU, BRCA2-deficient cells can resume DNA synthesis, but in contrast to BRCA2 $2^{+/+}$controls, accumulate in the $\mathrm{G}_{2}$ or $M$ phases of the cell cycle with $4 N$ DNA content (Fig. 4D; data not shown), consistent with prolonged Chk2 activation as well as additional mitotic delays (Lee et al. 1999). Thus, our results indicate the destabilization of stalled replication forks in BRCA2-deficient cells is not merely the result of failure to activate

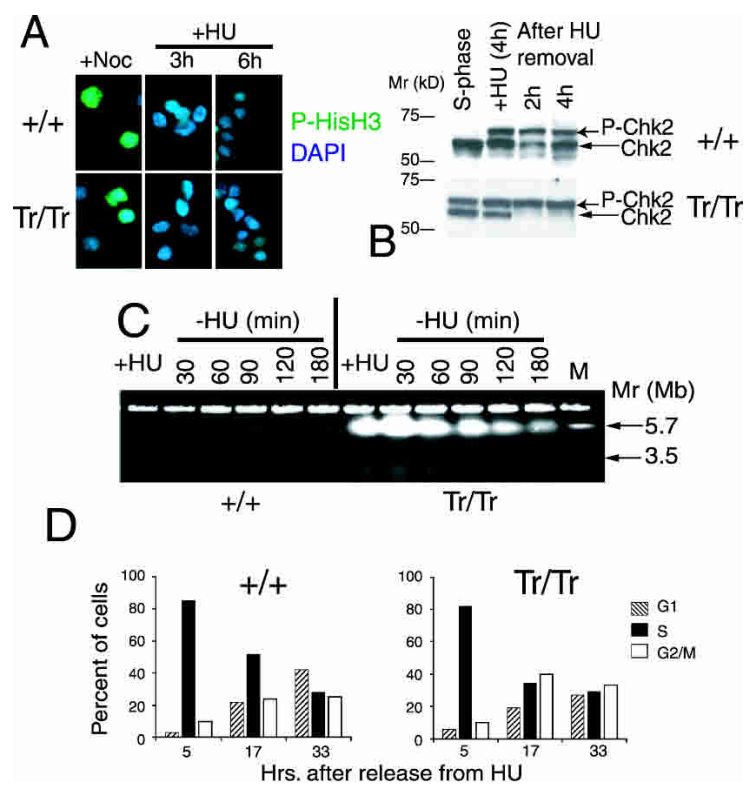

Figure 4. Checkpoint response to replication blockage. (A) Nuclei stained for phosphorylated histone $\mathrm{H} 3$ (P-HisH3, green), a marker for mitotic chromosomes, and DNA (DAPI, blue) before and during HU treatment. Staining after metaphase arrest induced by treatment with nocodazole (+Noc) for $16 \mathrm{~h}$ serves as a positive control. $(B)$ Chk2 activation in S phase-synchronized cells before $(-\mathrm{HU})$, during $\left(+\mathrm{HU} 240^{\prime}\right)$ and at $2 \mathrm{~h}$ and $4 \mathrm{~h}$ after removal of HU treatment is shown. Lines mark the migration of unmodified Chk2 and the retarded phospho-Chk2 (P-Chk2) bands. (C) Pulsed-field gel electrophoresis showing broken chromosomal DNA during (+HU) HU treatment, and at various times after removal of HU. (D) Cell cycle recovery after removal of $\mathrm{HU}$. After exposure to $5 \mathrm{mM} \mathrm{HU}$ for $4.5 \mathrm{~h}$, cells were released from $\mathrm{HU}$, and cell cycle profiles were determined by flow cytometry. The percentage of cells in the $G_{1}, S$, and $G_{2} / M$ phases is shown at 5 to $33 \mathrm{~h}$ after removal of HU.
Chk2, defining a novel role for BRCA2 in the response of mammalian cells to replication arrest.

\section{Implications}

We have previously shown that DNA double-strand breaks accumulate in dividing BRCA2Tr/Tr cells, giving rise to spontaneous chromosomal translocations that promote genetic instability and carcinogenesis ( $\mathrm{Yu}$ et al. 2000). Here, we present evidence that these breaks arise from stalled replication forks, implicating a normal physiological process-DNA replication-as a source of endogenous DNA breakage in a human genetic disease associated with chromosomal instability and cancer predisposition. Indeed, there is mounting evidence from bacterial models that replication forks frequently stall during normal DNA replication at DNA lesions, or template-bound proteins (Cox et al. 2000; Gregg et al. 2002). However, stalling does not usually give rise to persistent DNA breakage, pointing to the importance of mechanisms that deal with stalled replication in maintaining the integrity of chromosome structure. The findings we report here demonstrate that BRCA2 is an essential component of corresponding mechanisms in mammalian cells, and provide a first example connecting their failure with disease pathogenesis.

In yeast, the Rad53 protein, an ortholog of mammalian Chk2, is responsible for replication fork integrity after replication inhibition (Lopes et al. 2001). We find, however, that replication checkpoint arrest and Chk2 activation are unimpaired in BRCA2Tr/Tr cells, indicating that the function of BRCA2 in preserving the structure of stalled replication forks either is independent of Chk 2 or works in addition to Chk2 at a downstream point in the pathway.

Thus, our work not only implicates BRCA2 in the response to stalled replication but also defines a novel function in preserving the stability of stalled forks, providing a mechanistic basis for the DNA breakage that accompanies replication arrest when the function of BRCA2 is compromised. How BRCA2 stabilizes DNA junctions at stalled replication forks is not clear. One possibility is that it works through the RAD51 recombinase, which sheaths single-stranded DNA substrates to mediate strand exchange reactions, and which has activity that is regulated through its direct interaction with BRCA2 (for review, see Venkitaraman 2002). However, direct evaluation of the role of RAD51 in replication fork stability is rendered difficult by the rapid death of RAD51-deficient cells (Lim and Hasty 1996; Tsuzuki et al. 1996).

We propose that BRCA2 deficiency provides a first example of a disease triggered by the inability to respond to stalled DNA replication. This proposal may be relevant to other human cancer-prone diseases characterized by spontaneous chromosomal instability, such as variant Li-Fraumeni syndrome involving Chk2 mutations, Bloom syndrome, or Fanconi anemia, for several reasons. The cellular manifestations of these diseases resemble BRCA2 deficiency in many respects, the yeast homolog of each of these molecules has been implicated in recovery from replication arrest, and mutations in BRCA2 have recently been identified in certain complementation groups of Fanconi anemia (Howlett et al. 2002). Thus, our work emphasizes the importance of stalled replication forks as a potential source of spontaneous 
DNA breakage —an "endogenous mutagen"—in dividing cells, which may in part explain the etiology of certain human chromosomal instability disorders.

\section{Materials and methods}

\section{Cell cycle analyses}

Harvested cells were fixed with $70 \%$ cold ethanol for at least $30 \mathrm{~min}$ at +4 , washed and stained with propidium iodide, and analyzed by flowcytometry. For detection of mitotic cells, staining was with a 1:400 dilution of rabbit anti-phospho H3 (Upstate Biotechnology) or 1:100 dilution of murine anti-MPM2 (Upstate), revealed with Alexafluor488-conjugated anti-rabbit or anti-mouse secondary antibody (Molecular Probes). Microscopy was carried out on a Zeiss Axiovert system by using ZeissVision software. Cell cycle profiles or anti-MPM2 staining were analyzed by flow-cytometry as published (Patel et al. 1998; Lee et al. 1999).

$2 D$ gel electrophoresis

To preserve its secondary structure, DNA was isolated by embedding MEFs (either S phase synchronized by treatment with $1.4 \mu \mathrm{M}$ aphidicolin [Sigma] for $12 \mathrm{~h}$, or asynchronous) in agarose blocks before, and at different times after, exposure to $5 \mathrm{mM} \mathrm{HU}$. Cells were in their first culture passage within $2 \mathrm{~d}$ after isolation. Blocks (containing $1 \times 10^{6}$ cells each in $0.1 \mathrm{~mL}$ ) were agitated in a large volume of $0.5 \mathrm{mg} / \mathrm{mL}$ proteinase $\mathrm{K} / 1 \%$ Sarkosyl (BDH) for $6 \mathrm{~h}$ at $37^{\circ} \mathrm{C}$, washed, and digested with 500 units of ApaLl restriction enzyme (New England Biolabs) in $4 \mathrm{~mL}$ of ApaL1 buffer for $12 \mathrm{~h}$ at $37^{\circ} \mathrm{C}$. Neutral/neutral gel electrophoresis was carried out by using conditions described by Friedman and Brewer (1995), using a 0.35\% agarose gel in the first dimension and a $1 \%$ agarose gel in the second. DNA was transferred to nylon membranes (Amersham) and blotted with a 325-bp rDNA probe prepared by polymerase chain reaction using the primers 5'-CGCTGCGCGTACTTTCCTC-3' and 5'-TCAACGCCAGA CACGGACCC-3', labeled with 32-P dCTP (Amersham) by a random priming reaction. Quantitation of the Y-arc signal was carried out on a Storm 820 densitometer (Molecular Dynamics) using ImageQuant software. A ratio was calculated over signal intensity on the gel diagonal to correct for differences in DNA loading between different gels.

\section{Differential 14C/3H labeling}

Genomic DNA was labeled to saturation with [2-14C]-thymidine (Amersham) at $500 \mathrm{nCi}$ per $5 \times 10^{5}$ cells over $24 \mathrm{~h}$ before adding aphidicolin to $1.4 \mu \mathrm{M}$ for $12 \mathrm{~h}$. Then cells were washed from $14 \mathrm{C}$ and aphidicolin and left for $3 \mathrm{~h}$. To label nascent DNA, 3H-thymidine (Amersham) was added to $\mathrm{S}$ phase-synchronized cells at $2 \mu \mathrm{Ci} / \mathrm{mL}(4 \mu \mathrm{Ci}$ total $)$ per $5 \times 10^{5}$ cells. For the experiment in Figure 2A, 3H-thymidine was added $30 \mathrm{~min}$ before adding $\mathrm{HU}$, as well as for the experiment in Figure 2B for the indicated 2-h periods during $\mathrm{HU}$ treatment. Incorporation of $14 \mathrm{C}$ and $3 \mathrm{H}$ labels into DNA was measured after TCA precipitation using a Beckman scintillation counter. The $3 \mathrm{H} / 14 \mathrm{C}$ ratio for each data point represents the mean of three observations.

\section{Pulsed-field gel electrophoresis}

High-molecular-weight genomic DNA was prepared in agarose blocks, as described above for 2D gel electrophoresis, and run on a $0.6 \%$ agarose gel for $48 \mathrm{~h}$ on a CHEF-DRII apparatus (BioRad) at $90 \mathrm{~V}$ with a 15-min field switch time. Resolved DNA was blotted to nylon membranes before probing with the same rDNA probe used to detect replication intermediates. A 300-bp probe located $3.5 \mathrm{kbp} \mathrm{3'}$ of the bidirectional replication origin in the ADA locus was generated by PCR on mouse genomic DNA with primers: 5'-CTGAGGACACGGATGGCAAT-3' and 5'-GACAGA AGCGTGGTGGAGTT-3'. For the HPRT locus, a probe was generated from murine cDNA with primers: 5'-GTTGGATAC AGGCCAGACTT TGTTG-3' and 5'-GAGGGTAGGCTGGCCTATAGGCT-3'. Quantitation of rDNA fragmentation was by densitometry as described above. Gels stained with ethidium bromide were quantitated with an Alpha Innotech GelDoc system, using manufacturer's software.

\section{Western blotting}

For detection of Chk2, $50 \mu \mathrm{g}$ of protein extracted from cells in RIPA buffer per sample, was resolved by $7 \%$ SDS-PAGE, blotted, and stained with an antibody against murine Chk2 (BD Transduction Laboratories) at 1:500 dilution, using published methods.

\section{Acknowledgments}

The experiments reported in this article were conceived and performed by M.L., S.A., M.S., and A.V. R.D. obtained our first data on Chk2 activation in BRCA2-deficient cells. We thank Andy Riddell for expert assistance with flow cytometry, Mark Madine and Ron Laskey for constructive criticism of this manuscript, and members of our laboratory for helpful discussions. M.L. is supported by the Leukaemia Research Fund, UK and the Medical Research Council; S.A. and M.S., by Cancer Research UK.

The publication costs of this article were defrayed in part by payment of page charges. This article must therefore be hereby marked "advertisement" in accordance with 18 USC section 1734 solely to indicate this fact.

\section{References}

Alcasabas, A.A., Osborn, A.J., Bachant, J., Hu, F., Werler, P.J., Bousset, K., Furuya, K., Diffley, J.F., Carr, A.M., and Elledge, S.J. 2001. Mrc1 transduces signals of DNA replication stress to activate Rad53. Nat. Cell. Biol. 3: 958-965.

Boddy, M.N., Furnari, B., Mondesert, O., and Russell, P. 1998. Replication checkpoint enforced by kinases Cds1 and Chk1. Science 280: 909-912.

Carroll, S.M., DeRose, M.L., Kolman, J.L., Nonet, G.H., Kelly, R.E., and Wahl, G.M. 1993. Localization of a bidirectional DNA replication origin in the native locus and in episomally amplified murine adenosine deaminase loci. Mol. Cell. Biol. 13: 2971-2981.

Chaturvedi, P., Eng, W.K., Zhu, Y., Mattern, M.R., Mishra, R., Hurle, M.R., Zhang, X., Annan, R.S., Lu, Q., Faucette, L.F., et al. 1999. Mammalian Chk2 is a downstream effector of the ATM-dependent DNA damage checkpoint pathway. Oncogene 18: 4047-4054.

Chen, C. and Kolodner, R.D. 1999. Gross chromosomal rearrangements in Saccharomyces cerevisiae replication and recombination defective mutants. Nat. Genet. 23: 81-85.

Chen, J., Silver, D.P., Walpita, D., Cantor, S.B., Gazdar, A.F., Tomlinson, G., Couch, F.J., Weber, B.L., Ashley, T., Livingston, D.M., et al. 1998. Stable interaction between the products of the BRCA1 and BRCA2 tumor suppressor genes in mitotic and meiotic cells. Mol. Cell 2: 317-328

Cliby, W.A., Roberts, C.J., Cimprich, K.A., Stringer, C.M., Lamb, J.R., Schreiber, S.L., and Friend, S.H. 1998. Overexpression of a kinaseinactive ATR protein causes sensitivity to DNA-damaging agents and defects in cell cycle checkpoints. EMBO T. 17: 159-169.

Cohen, S.M., Brylawski, B.P., Cordeiro-Stone, M., and Kaufman, D.G. 2002. Mapping of an origin of DNA replication near the transcriptional promoter of the human HPRT gene. J. Cell. Biochem. 85: 346356.

Cox, M.M., Goodman, M.F., Kreuzer, K.N., Sherratt, D.J., Sandler, S.J., and Marians, K. J. 2000. The importance of repairing stalled replication forks. Nature 404: 37-41.

Dimitrova, D.S. and Gilbert, D.M. 2000. Temporally co-ordinated assembly and disassembly of replication factories in the absence of DNA synthesis. Nat. Cell Biol. 2: 686-694.

Enoch, T., Carr, A.M., and Nurse, P. 1992. Fission yeast genes involved in coupling mitosis to completion of DNA replication. Genes \& DeV. 6: $2035-2046$

Friedman, K.L. and Brewer, B.J. 1995. Analysis of replication intermediates by two-dimensional agarose gel electrophoresis. Methods Enzymol. 262: 613-627.

Friedman, L.S., Thistlethwaite, F.C., Patel, K.J., Yu, V.P., Lee, H., Venkitaraman, A.R., Abel, K.J., Carlton, M.B., Hunter, S.M., Colledge, W.H., et al. 1998. Thymic lymphomas in mice with a truncating mutation in Brca2. Cancer Res. 58: 1338-1343.

Gao, W.Y., Zhou, B.S., Johns, D.G., Mitsuya, H., and Yen, Y. 1998. Role of the M2 subunit of ribonucleotide reductase in regulation by hydroxyurea of the activity of the anti-HIV-1 agent $2^{\prime}, 3^{\prime}$-dideoxyinosine. Biochem. Pharmacol. 56: 105-112.

Gerber, J.K., Gogel, E., Berger, C., Wallisch, M., Muller, F., Grummt, I., and Grummt, F. 1997. Termination of mammalian rDNA replication Polar arrest of replication fork movement by transcription termination factor TTF-I. Cell 90: 559-567.

Gogel, E., Langst, G., Grummt, I., Kunkel, E., and Grummt, F. 1996. 
Mapping of replication initiation sites in the mouse ribosomal gene cluster. Chromosoma 104: 511-518.

Gregg, A.V., McGlynn, P., Jaktaji, R.P., and Lloyd, R.G. 2002. Direct rescue of stalled DNA replication forks via the combined action of PriA and RecG helicase activities. Mol. Cell 9: 241-251.

Gretarsdottir, S., Thorlacius, S., Valgardsdottir, R., Gudlaugsdottir, S., Sigurdsson, S., Steinarsdottir, M., Jonasson, J.G., Anamthawat-Jonsson, K., and Eyfjord, J.E. 1998. BRCA2 and p53 mutations in primary breast cancer in relation to genetic instability. Cancer Res. 58: 859862 .

Hirao, A., Kong, Y.Y., Matsuoka, S., Wakeham, A., Ruland, J., Yoshida, H., Liu, D., Elledge, S.J., and Mak, T.W. 2000. DNA damage-induced activation of p53 by the checkpoint kinase Chk2. Science 287: 18241827.

Howlett, N.G., Taniguchi, T., Olson, S., Cox, B., Waisfisz, Q., De DieSmulders, C., Persky, N., Grompe, M., Joenje, H., Pals, G., et al. 2002. Biallelic inactivation of BRCA2 in Fanconi anemia. Science 297: 606609.

Lee, H., Trainer, A.H., Friedman, L.S., Thistlethwaite, F.C., Evans, M.J., Ponder, B.A., and Venkitaraman, A.R. 1999. Mitotic checkpoint inactivation fosters transformation in cells lacking the breast cancer susceptibility gene, Brca2. Mol. Cell 4: 1-10.

Levenson, V. and Hamlin, J.L. 1993. A general protocol for evaluating the specific effects of DNA replication inhibitors. Nucleic Acids Res. 21: 3997-4004.

Lim, D.S. and Hasty, P. 1996. A mutation in mouse rad51 results in an early embryonic lethal that is suppressed by a mutation in p53. Mol. Cell. Biol. 16: 7133-7143.

Lopes, M., Cotta-Ramusino, C., Pellicioli, A., Liberi, G., Plevani, P., Muzi-Falconi, M., Newlon, C.S., and Foiani, M. 2001. The DNA replication checkpoint response stabilizes stalled replication forks. $\mathrm{Na}$ ture 412: 557-561.

Michel, B., Ehrlich, S.D., and Uzest, M. 1997. DNA double-strand breaks caused by replication arrest. EMBO J. 16: 430-438.

Myung, K., Datta, A., and Kolodner, R.D. 2001. Suppression of spontaneous chromosomal rearrangements by $\mathrm{S}$ phase checkpoint functions in Saccharomyces cerevisiae. Cell 104: 397-408.

Nathanson, K.L., Wooster, R., Weber, B.L., and Nathanson, K.N. 2001. Breast cancer genetics: What we know and what we need. Nat. Med. 7: 552-556.

Patel, K.J., Yu, V.P., Lee, H., Corcoran, A., Thistlethwaite, F.C., Evans, M.J., Colledge, W.H., Friedman, L.S., Ponder, B.A., and Venkitaraman, A.R. 1998. Involvement of Brca2 in DNA repair. Mol. Cell 1: 347-357.

Scully, R. and Livingston, D.M. 2000. In search of the tumour-suppressor functions of BRCA1 and BRCA2. Nature 408: 429-432.

Tercero, J.A. and Diffley, J.F. 2001. Regulation of DNA replication fork progression through damaged DNA by the Mec1/Rad53 checkpoint. Nature 412: 553-557.

Tsuzuki, T., Fujii, Y., Sakumi, K., Tominaga, Y., Nakao, K., Sekiguchi, M., Matsushiro, A., Yoshimura, Y., and Morita, T. 1996. Targeted disruption of the Rad51 gene leads to lethality in embryonic mice. Proc. Nat1. Acad. Sci. 93: 6236-6240.

Venkitaraman, A.R. 2000. The breast cancer susceptibility gene, BRCA2: At the crossroads between DNA replication and recombination? Philos. Trans. R. Soc. Lond. B Biol. Sci. 355: 191-198.

2002. Cancer susceptibility and the functions of BRCA1 and BRCA2. Cell 108: 171-182.

Versini, G., Comet, I., Wu, M., Hoopes, L., Schwob, E., and Pasero, P. 2003. The yeast Sgs1 helicase is differentially required for genomic and ribosomal DNA replication. EMBO J. 22: 1939-1949.

Yu, V.P., Koehler, M., Steinlein, C., Schmid, M., Hanakahi, L.A., van Gool, A.J., West, S.C., and Venkitaraman, A.R. 2000. Gross chromosomal rearrangements and genetic exchange between nonhomologous chromosomes following BRCA2 inactivation. Genes \& Dev. 14: 1400-1406.

Zhao, X., Muller, E.G., and Rothstein, R. 1998. A suppressor of two essential checkpoint genes identifies a novel protein that negatively affects dNTP pools. Mol. Cell 2: 329-340. 


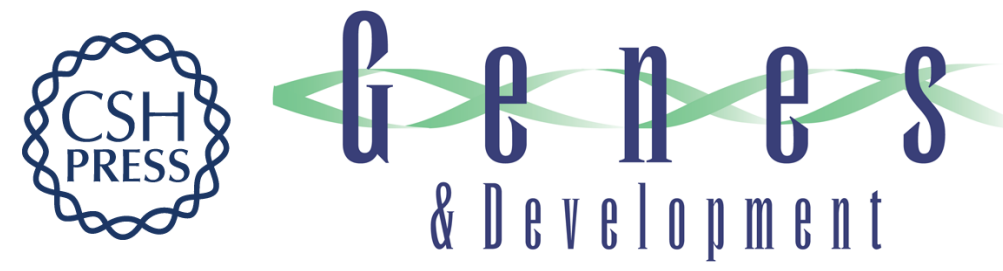

\section{Stabilization of stalled DNA replication forks by the BRCA2 breast cancer susceptibility protein}

Mikhail Lomonosov, Shubha Anand, Mahesh Sangrithi, et al.

Genes Dev. 2003, 17:

Access the most recent version at doi:10.1101/gad.279003

$\begin{array}{ll}\text { References } & \begin{array}{l}\text { This article cites } 36 \text { articles, } 13 \text { of which can be accessed free at: } \\ \text { http://genesdev.cshlp.org/content/17/24/3017.full.html\#ref-list-1 }\end{array}\end{array}$

License

Email Alerting Receive free email alerts when new articles cite this article - sign up in the box at the top Service right corner of the article or click here.

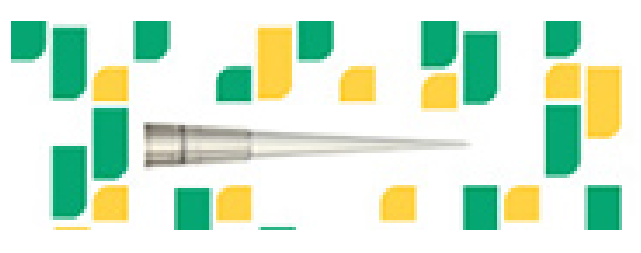

Focused on your science. 